\title{
Does state budget pressure matter for uncompensated care spending in hospitals? Findings from Texas and California ${ }^{\dagger}$
}

\author{
Jongwha Chang ${ }^{1}$, Isha Patel ${ }^{2}$, Won S. Suh ${ }^{3 *}$, Hsien-Chang Lin ${ }^{4}$, \\ SunJung $\mathrm{Kim}^{5}$ and Rajesh Balkrishnan ${ }^{2,6}$ \\ ${ }^{1}$ Department of Public Health Sciences, The Pennsylvania State University, Hershey, PA, USA \\ ${ }^{2}$ Department of Social and Administrative Sciences, University of Michigan, Ann Arbor, MI, USA \\ ${ }^{3}$ Department of Global Healthcare Management, Gachon University, Seoul, Korea \\ ${ }^{4}$ Department of Applied Health Science, Indiana University, Bloomington, IN, USA \\ ${ }^{5}$ Strategy and International Business Development, Seoul National University Hospital, \\ Seoul, Korea \\ ${ }^{6}$ Department of Health Management and Policy, University of Michigan, Ann Arbor, MI, USA
}

\section{SUMMARY}

Objective This study examined the impact of state budget cuts on uncompensated care at general acute care hospital organizations. This study capitalized on the variations in the states of Texas and California to form a natural experiment testing the joint impact of budget cut status on uncompensated care costs, as well as specific charity care costs and bad debt expenses from indigent patients.

Methodology Budget cuts in the state of Texas occurred in the year 2004. Information was obtained from the Texas Department of Health and the California Department of Health Services regarding financial characteristics of hospitals and from the American Hospital Directory annual survey regarding organizational characteristics of hospitals. We created three dependent variables: $R_{\mathrm{UC}}$ (the ratio of total uncompensated care costs to gross patient revenue), $R_{\mathrm{CC}}$ (the ratio of charity care to total patient revenue) and $R_{\mathrm{BD}}$ (the ratio of bad debt expenses to gross patient revenue). Using a two-period panel data set and individual hospital fixed effects, we captured hospital uncompensated care spending that could also have influenced budget cut status. Additionally, the impact of the state budget cut status on hospitals' uncompensated care spending, charity care spending and bad debt expenses was also estimated using the similar methodology. Population studied In this study, we included 416 (in Texas) and 352 (in California) public, not-for-profit (NFP) and for-profit (FP) hospitals that completed the annual survey during the study period 2002-2005.

Findings For the state of Texas, results from the fixed effect model confirmed that the year 2005 was directly related to increased $R_{\mathrm{UC}}$ and $R_{\mathrm{CC}}$. The coefficients of 2005 were significantly and positively associated with $R_{\mathrm{UC}}(0.43, p<0.05)$ and $R_{\mathrm{CC}}(0.29, p<0.05)$. These results supported the findings that the $R_{\mathrm{UC}}$ and the $R_{\mathrm{CC}}$ would be more positively associated with 2005 than any other year, with other things being equal. However, for the state of California, even though the coefficient of 2005 was significant and positively associated with $R_{\mathrm{CC}}(0.31, p<0.05)$, the coefficient of uncompensated care spending was not statistically significant for 2005 .

*Correspondence to: Won S. Suh, Department of Global Healthcare Management, Gachon University, Seoul, Korea. E-mail: suhw@gachon.ac.kr

This research was supported by Gachon University 2012. 
Conclusion The healthcare industry is characterized by increased regulation, a growing number of uninsured patients, increasingly stringent reimbursement and competitive practices among hospitals and other providers. Federal and state healthcare agencies are restricting the criteria for eligibility for outlier payments and uncompensated care provisions. Tax exempt status of many NFP hospitals is being examined and tied to specific performances, particularly the provision of uncompensated care. This study provides evidence of the impact of budget cut pressure on uncompensated care provided in Texas general acute care hospitals. Copyright ( $) 2012$ John Wiley \& Sons, Ltd.

KEY WORDS: state budget pressure; uncompensated care; acute hospitals; hospitals' spending

\section{INTRODUCTION}

According to an estimate provided by the Centers for Medicare and Medicaid Services (2010), the US healthcare industry amounted to \$2.3 trillion in 2008 compared with $\$ 253$ billion about two decades ago. In 2004, the American Hospital Association reported that about $73 \%$ of 5759 hospitals established in the society consist of private not-for-profit (NFP) hospitals (AHA, 2004). These hospitals perform the role of providing charity care services and subsidized services to indigent Americans nationwide. A classical case can be seen with the state of Texas, which faced one of the largest revenue drops of about $\$ 7.4$ billion and an estimated deficit of $\$ 9.9$ billion. These figures represented about 15\% of the general revenue spending for FY 2004-2005 biennium. The shortfall in Texas in terms of this dramatic revenue decrease was attributed to the increased state spending on Medicaid and State Children's Health Insurance Program (SCHIP). Policy makers concluded that the only solution that could resolve budget crisis was to reduce the burden of this health-related expenditure (Hadley and Holahan, 2004).

Historically, internal cross-subsidization has been rampant in US hospitals that use surplus from the government to cover the costs of uncovered services or uncompensated care (Vladeck, 2006; Simpson and Shin, 1998). Weissman defines uncompensated care as the sum of charity care and bad debt expenses (Weissman, 2005). Charity care is the amount that hospitals spend to provide services on a charitable basis without any payment expectation. On the other hand, bad debt expenses comprise the amount that hospitals spend for provision of services with the expectation of complete payments but for which only partial payments are received (Desai et al., 2000; Young and Desai, 1999). The year 2004 saw the highest number of uninsured patients in the state of Texas compared with other states in the USA, with as high as 5.4 million uninsured people (US Census, 2004). Thus, given the prevalence of the critical financial status of hospitals, (i) the growth in government spending in healthcare due to the aging baby boomers and (ii) the tax benefits and exemptions enjoyed by hospitals make it important to determine an equitable and reliable measure of uncompensated care expenditure. An unconventional trend, compared with the remainder of the US states, could be witnessed while studying the consequences of budget cut in Texas on its SCHIP enrollment. According to the report of the Kaiser Commission on Medicaid and the Uninsured, there was an increment in the national SCHIP enrollment by around 25000 (an increase of $0.6 \%$ ) during the period from December 2003 to 
December 2004. During this period, majority of the states, that is, about 35 states, had increased SCHIP enrollment, but 13 states had decreased SCHIP enrollment. Texas had the largest decline in SCHIP enrollment, with a drop of $23 \%$ that consists of about 102000 enrollees. SCHIP enrollment continued to decrease in 2004, dropping from 438000 in December 2003 to 360000 in June 2004. This decline continued in the upcoming months, with only 336000 people enrolled in SCHIP by December 2004 (Kaiser Commission on Medicaid and the Uninsured, 2005). Another Kaiser Family Foundation report confirmed that the drastic decline in Texas SCHIP enrollment by more than 149000 children (about 29\%) was due to the impact of state budget cuts 2004. The primary reason leading to this decline in Texas was the reduced enrollment in SCHIP and the increased disenrollment of already enrolled children (Kaiser Commission on Medicaid and the Uninsured, 2004).

According to Thorpe et al. (2000), uncompensated care provided by US hospitals amounts to a large sum of $\$ 30$ billion. The emergence of uncompensated charges in the form of provision of care for the seriously ill and non-paying indigent patients occurring in an environment of increasing costs and curtailed revenues further precipitates in reduction of revenues, surmounting costs and shift of resources from paying patients to non-paying patients (GAO, 2005; Fishman and Bentley, 1997). In the current scenario where hospitals are facing a tremendous increase in the number of uninsured patients, they are accused of charity shifting to self-pay patients. Phelps indicates that when Medicare or public agencies reduce the amounts that they pay to the hospitals for inpatient care, hospitals indulge in charge shifting, which involves recovering some of their costs by raising prices for privately insured patients (Phelps, 1986; Wedig et al., 1988). The financial viability of healthcare providers serving indigent population is jeopardized by state budget cut pressure in a number of ways primarily affecting provider payment rates, provider ability to treat indigent patients and benefit cuts. State budget cut pressure poses a dual threat of not only endangering a provider's revenue but also increasing the burden of uncompensated care (Hoadley et al., 2004; Wright, 1998; Mann et al., 1995; Melnick and Zwanziger, 1995).

Several studies have examined the structure of hospital costs. Patients admitted through the emergency department (ED) experience higher disease burden and will incur higher costs compared with other patients. The healthcare costs incurred owing to ED-related admissions lead to further increase in inpatient costs because ED patients receive services generally procured outside the hospital such as various routine diagnostic tests, screenings and regular procedures (Gaynor and Anderson, 1995; Robinson and Luft, 1985; Grannemann et al., 1986; Dor and Farley, 1996). Also, most of the patients admitted through ED are uninsured, avoid primary care services, are hospitalized when their disease condition advances and require a long recovery time. Thus, the length of hospital stay for ED patients is much longer compared with other patients. One research study in New York showed evidence that on average, patients admitted through ED stayed in the hospital for 5 days extra compared with patients admitted through outpatient departments and about 3 days extra compared with patients admitted by a healthcare practitioner (Gaynor and Anderson, 1995; Harris and Stergachis, 1990). Hospitals located in the metropolitan areas provide care to a large number of uninsured populations compared with 
hospitals located in the non-metropolitan areas. The costs of treating poor patients is much more than treating patients who are not poor even though they belong to the same diagnosis-related group (DRG). Higher treatment costs incurred by providing care for the severely ill are not sufficiently measured by the existent case mix indexes (CMIs). This might lead to further increase in uncompensated care. Evidence from previous literature shows that case mix, teaching affiliation, bed size and hospital location have an impact on unit costs. Hospitals located in the metropolitan areas provide care to a large number of uninsured populations compared with hospitals located in the non-metropolitan areas. The cost of treating of poor patients is much more than treating patients who are not poor even though they belong to the same DRG (Martin et al., 1984; Davis, 1991).

The increase in Medicare and Medicaid fees for service payments from 1990 to 1998 helped alleviate the burden of uncompensated care shouldered by the hospitals. The payment-to-cost ratio increased from 89.2\% to 103.6\% for Medicare from 1990 to 1997 and from $79.7 \%$ to $97.9 \%$ for Medicaid from 1990 to 1998, respectively.

However, with the emergence of the Balanced Budget Act (BBA) of 1997 and increase in the number of managed care enrollees, the payment-to-cost ratio fell in 1999 to $101.1 \%$ and $96.7 \%$ for Medicare and Medicaid, respectively. The initiation of the Disproportionate Share Hospital (DSH) program provided financial assistance to hospitals providing care to Medicaid and Medicare populations. The Medicaid funding for the DSH program, which was increased from $\$ 800$ million in 1990 to $\$ 10.6$ billion in 1995, was cut short because of the BBA in 1997. This cutback in funding not only led the hospitals to restrict healthcare access to poor people but also threatened the viability of the hospitals playing a major role in providing uncompensated care according to the community needs. Medicaid patients receive higher uncompensated care compared with Medicare patients (Hsieh and Clement, 2010; Coughlin and Liska, 1997). Teaching hospitals also incur more uncompensated care because they take in patients with a variety of disease conditions. The patients provide educational value to the medical graduates, and the medical education payments from Medicare help to offset some of the uncompensated care expenses. They also are more likely to be larger than non-teaching hospitals and are located in urban and economically depressed inner-city areas (HCIA, 1997). The graduate medical education payment is majorly supported by Medicare. With the emergence of the BBA in 1997, Medicare reduced these payments from $7.7 \%$ (accounting for every $10 \%$ increase in the ratio of residents to bed) to $7.0 \%, 6.5 \%$ and $6.0 \%$ in 1998 , 1999 and 2000, respectively. The reduction in medical education payments covered by Medicare not only forced the hospitals to support a limited number of medical residents but also increased the burden of uncompensated care for the urban teaching hospitals (Rosko, 2004a, b).

To our knowledge, this is one of the few studies trying to find systematic evidence about price elevation witnessed in Texas hospitals for procuring healthcare services to inflate escalated uncompensated care expenditure during the budget cut crisis of 2004. This analysis adds to the prior literature by investigating the factors that might relate the utilization of uncompensated care to the location of hospitals, as a means to mitigate state budget cut pressure as well as management of net revenues reported. It tries to identify and characterize the group of hospitals on the basis of provision of 
uncompensated care during the period before and after the emergence of budget cut crisis in Texas. This study aimed to measure and evaluate uncompensated care by comparing it with total costs and net patient revenue revealed by the financial statements of hospitals. Specifically, this study aimed to compare the components of uncompensated care, that is, charity care and bad debt expenses, with deductions from net hospital revenues. It also scrutinizes the difference, if any, in the association of reported uncompensated care and the state budget cut pressure of 2004.

\section{DATA AND METHODS}

To assess how hospitals adjust their prices and their level of reported uncompensated care in response to increased financial and political pressures, data sources were obtained from the Texas Department of Health and the California Department of Health Services regarding financial characteristics of hospitals and from the American Hospital Directory annual survey regarding organizational characteristics of hospitals. We included general acute care hospitals in the analyses and excluded specialty hospitals (facilities that emphasize long-term care) and psychiatry hospitals for comparability reasons and owing to variations in different reimbursement systems. We also excluded all federal hospitals, which are mainly Veterans Administration and military hospitals, as they serve a separate population, which makes them incomparable. In the sample period 2005-2006, 416 public, NFP and for-profit (FP) hospitals in Texas and 352 public, NFP and FP hospitals in California completed the annual survey.

We created three ratios as outcome variables in this study. $R_{\mathrm{UC}}$ is the ratio of total uncompensated care costs to gross patient revenue. $R_{\mathrm{CC}}$ is the ratio of charity care to gross patient revenue. $R_{\mathrm{BD}}$ is the ratio of bad debt charge to gross patient revenue. $R_{\mathrm{UC}}, R_{\mathrm{CC}}$ and $R_{\mathrm{BD}}$ are hospital spending values derived as follows:

$$
\begin{gathered}
R_{\mathrm{UC}}=\text { Total uncompensated care/Total gross patient revenues } \\
R_{\mathrm{CC}}=\text { Total charity care/Total gross patient revenues } \\
R_{\mathrm{BD}}=\text { Total bad debt charges } / \text { Total gross patient revenues }
\end{gathered}
$$

We performed trend and comparative analyses for the dependent variables to examine the change in the historical financial ratios distribution. The mean values and tests of the mean differences among 2002, 2003 and 2005 were derived for the aforementioned three samples and for the following variables:

$$
\text { CHR }=\text { Charity care }(\text { in dollars })
$$

UNC uncompensated care $=$ Charity care + Bad debt

$$
\mathrm{BD}=\text { Bad debt charges }
$$

Tests of differences were conducted using both Student's $t$-test and signed rank test of differences. We calculated bad debt as a percentage of uncompensated care 
(bad debt and charity care) to determine whether the proportion of bad debt in uncompensated care changes across the test period. We also examined bad debt expenses as a percentage of revenue. The analysis of uncompensated care as a percentage of revenue was to determine whether uncompensated care changed as a result of any changes in bad debt. The explanatory model is of the following general form:

$$
R_{\mathrm{UC}}\left(R_{\mathrm{CC}}, R_{\mathrm{BD}}\right) h t=f(X h t, M h t)
$$

Measures of the primary dependent variables are the ratio of uncompensated care to gross patient revenue $\left(R_{\mathrm{UC}}\right)$. To be more specific, we created two more specific sub-dependent variables $\left(R_{\mathrm{CC}}\right.$ and $\left.R_{\mathrm{BD}}\right)$. The measure of the sub-dependent variables is the ratio of charity care and bad debt expenses to gross patient revenue, respectively. Thus, our independent variables were based on the hospital spending in Texas and California based on the ratios (of total uncompensated care, charity care and bad debt expenses) to gross patient revenue. Independent variables were based on prior literature review. Our proposed model contained a number of explanatory variables believed to influence uncompensated care. The primary independent variable was the year effect of budget cut pressure in 2004. We also included other independent covariates such as CMI, number of admissions in the hospitals, Medicare patient days as a percentage of total patient days, Medicaid patient days as a percentage of total patient days, average length of stay (ALOS) in the hospitals and occupancy rate of the hospitals. The Medicare Severity-Diagnosis Related Groups (MS-DRGs) classifies severity of a disease condition into three levels. CMI is defined as the average relative weight for all cases reported with regards to MS-DRGs at a particular severity level. MS-DRGs for disease conditions with lower severity have lower relative weights, and MS-DRGs for disease conditions with higher severity have higher relative weights. Generally, for determining the CMI, a "base" MS-DRG is used, which combines the different levels of disease severity into a single level. Base MS-DRGs with a single severity level are widely used for reporting as compared with MS-DRGs with variable severity levels. The number of admissions includes adult and pediatric patients who are admitted during the reported period. It does not include births but includes neonatal and swing admissions. The ALOS comprises of the average number of days that an adult or a pediatric patient is admitted in the hospital. The ALOS is calculated by dividing the total number of patient days by the number of patient admissions or patient discharges. A patient day is also called a census day or an inpatient day of care or an occupied bed day. An occupied bed day is calculated as the period during which a service is delivered between the census-taking hours on two successive calendar days provided that the discharge date is the same as the admission date. Occupancy rate is the number of inpatient days of care or the number of hospital bed days divided by the quantity of available beds in the hospital multiplied by the number of days for the specific year. Medicare inpatient days include inpatient days where Medicare is the source of payment. The care is funded for Medicare enrollees covered under the traditional fee-for-service plan or the Medicare Managed Care Plan. Medicare fee-for-service claims for inpatients are covered under the Inpatient Prospective Payment System (IPPS), which covers acute inpatient care such as operating expenses and other capital expenses. Payments under the IPPS are predetermined and are based on the patient's 
disease severity, treatment and hospital's market conditions. Under the IPPS system, Medicare inpatients can receive care for 60 consecutive days per episode of illness in a hospital or skilled nursing facility. Medicaid inpatient days include inpatient days where Medicaid acts as the source of payment. The care is funded for Medicaid enrollees covered under the traditional fee-for-service plan, the Medicaid Managed Care Plan, the Medicaid DSH and the Medicaid supplemental payments. The Medicaid supplemental payments are supplemental payments other than the Medicaid DSH payments paid by Medicaid to hospitals that exclude associated provider taxes or assessments (American Hospital Association, 2009; American Hospital Directory, 2009; Centers for Medicare and Medicaid Services, 2009; Dalpatadu et al., 2007). In addition, we included several hospital characteristics such as teaching status (teaching versus non-teaching), hospital governance (NFP, FP and public), hospital location (metropolitan versus non-metropolitan), and hospital bed size $(<25,26-100,101-250$ and $>250)$. Finally, to examine the impact of the state budget cut crisis, the use of a year dummy variable was included.

The samples consisted of 416 hospitals for Texas and 352 hospitals for California for each year that had NFP, FP and public hospitals by using reports of each state's Department of Health. In the multivariate analysis, we merged the data sets for of 2002, 2003 and 2005 into one data set. Separate fixed effects by hospitals for OLS regression analyses examined the impact of hospital size, ALOS, occupancy rate, Medicare and Medicaid patients' days, CMI, teaching status, and hospital governance on hospitals' uncompensated care, charity care and bad debt expenses spending with acute care hospitals for both states.

\section{RESULTS}

Table 1 shows the descriptive statistics of variables associated with uncompensated care during the test period. Before 2004, the means of bad debt and charity care expenses were \$7861275 and \$8600195 in Texas and \$5171235 and \$3900106 in California, respectively. For CMI, these were 1.20 (before 2004) and 1.18 (after 2004) in Texas. They were 1.29 (before 2004) and 1.28 (after 2004) in California. As far as hospital locations were concerned, about 298 hospitals $(71.46 \%)$ were located in a metropolitan area, and the remaining hospitals (28.54\%) were located in non-metropolitan areas in Texas. In California, there were 192 hospitals $(54.55 \%)$ located in the metropolitan areas, and the remaining 160 hospitals $(45.45 \%)$ were located in the non-metropolitan areas.

Table 2 indicates the mean differences among major variables (bad debt expenses, charity care and gross patient revenue) during the test period. The mean differences among all these three variables were statistically significant $(p<0.05)$ during the study period.

Results for uncompensated care, charity care, bad debt expenses and covariates are reported in Table 3. Results of the year effect variable confirm that 2005 was directly related to increased hospital spending of uncompensated care and charity care in Texas. The coefficients of the year effect of 2005 were significantly and positively associated with uncompensated care $(0.43, p<0.05)$ and charity care $(0.29, p<0.05)$. These results indicate that among the years 2002, 2003 and 2005, 


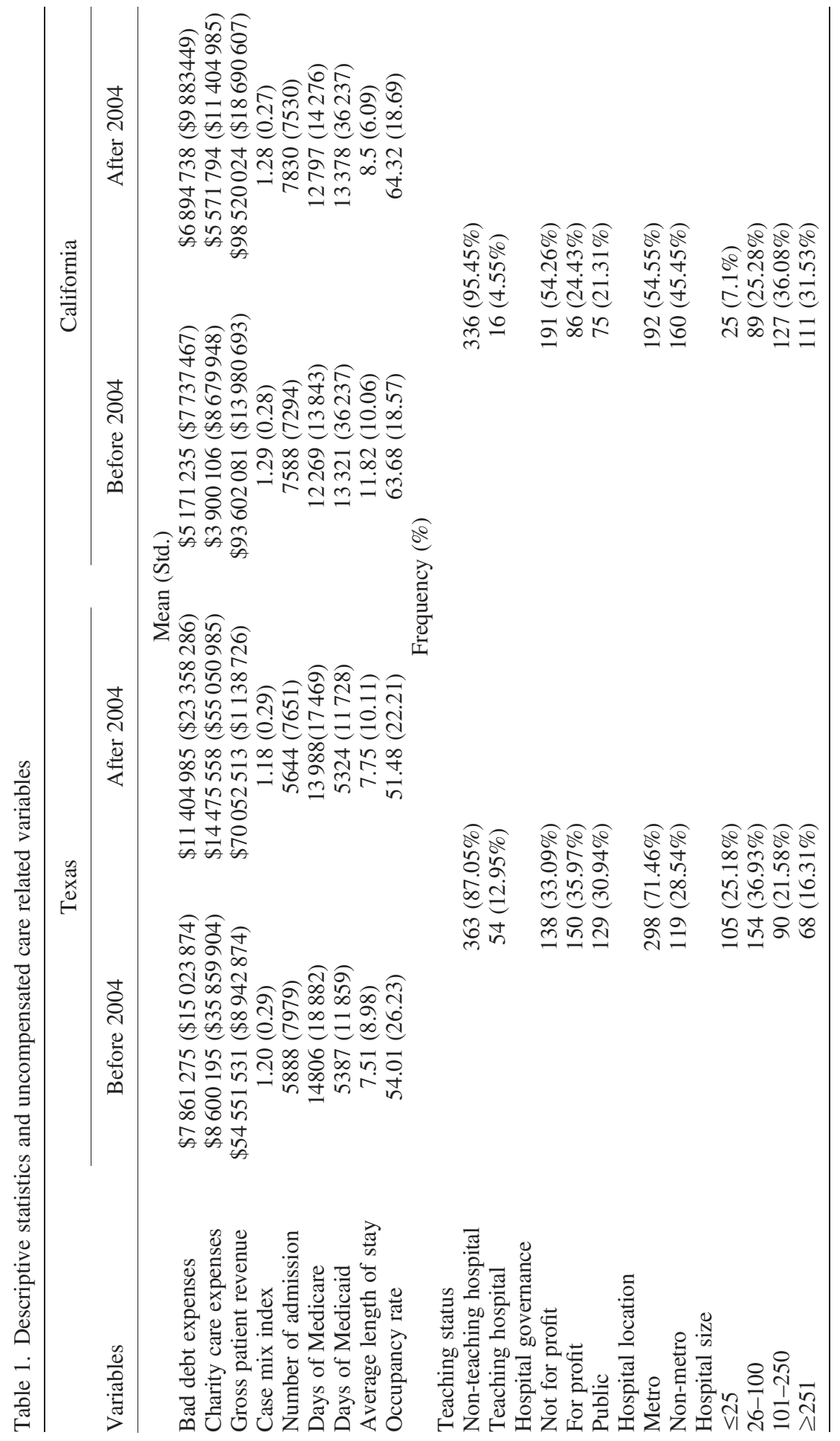

Copyright @ 2012 John Wiley \& Sons, Ltd.

Int J Health Plann Mgmt 2012; 27: 88-103. 
Table 2. Mean difference of major variables during the test period

\begin{tabular}{lcc}
\hline Major variables & Texas & California \\
\hline Bad debt expenses & $\$ 3543710^{*}$ & $\$ 1723503^{*}$ \\
Charity care & $\$ 5875363^{*}$ & $\$ 1671688^{*}$ \\
Gross patient revenue & $\$ 15500982^{*}$ & $\$ 4917943^{*}$ \\
\hline
\end{tabular}

$* p<0.05$.

with other things being equal, the spending of uncompensated care and charity care was more positively related to 2005 compared with 2002 and 2003.

Table 3 also shows that the spending for charity care was more positively related to NFP hospitals than for others. Compared with NFP hospitals in Texas, results for hospital governance indicate that FP hospitals were directly related to decreased spending of charity care $[-1.05(p<0.05)$ vs. $-1.88(p<0.1)]$ in Texas and California, respectively. Compared with 2002, 2003 and 2005, for CMI, the coefficients for uncompensated care and charity care were $1.23(p<0.1)$ and $0.85(p<0.1)$ in Texas, respectively. For hospitals located in the metropolitan areas in Texas, the coefficients for uncompensated care and charity care were $-0.28(p<0.05)$ and $-0.2(p<0.05)$, respectively, compared with hospitals located in the non-metropolitan areas. In California, the coefficients for uncompensated care and charity care for metropolitan hospitals were $-0.24(p<0.1)$ and $-0.18(p<0.1)$ compared with non-metropolitan hospitals.

\section{DISCUSSION}

The healthcare industry is regulated and burdened by a growing number of uninsured patients, increasingly stringent reimbursement and growing competition between hospitals and other providers. Federal and state healthcare agencies are increasing the standards of eligibility for outlier payments and uncompensated care provisions. Tax exempt status of many NFP hospitals is being examined and tied to specific performance, particularly the provision of uncompensated care. This study provides empirical evidence of the impact of the Texas budget cut pressure on provision of uncompensated care as reported by Texas acute care hospitals.

Community benefit includes healthcare assistance to Medicaid population and other indigent federal or state population in the form of donations, research, health programs and other related activities (Texas Health and Safety Code, 2007). The demand of community needs is a major driver of charity care delivered by hospitals. If the community needs are same as or more than the amount of care delivered by hospitals, then hospitals will either provide the necessary care or provide care surpassing their ability to deliver. On the other hand, some hospitals might also deliver charity care to the community in an amount proportionate to securing tax benefits (Bryce, 2001). Community benefit laws are different in California and Texas. Under the California community benefit law, hospitals' charity care is process oriented, and hospitals are supposed to submit a community benefits plan to the Office of Statewide Health Planning and Development every year. The hospitals are not obligated to provide any set amount of charity care (California Health and 


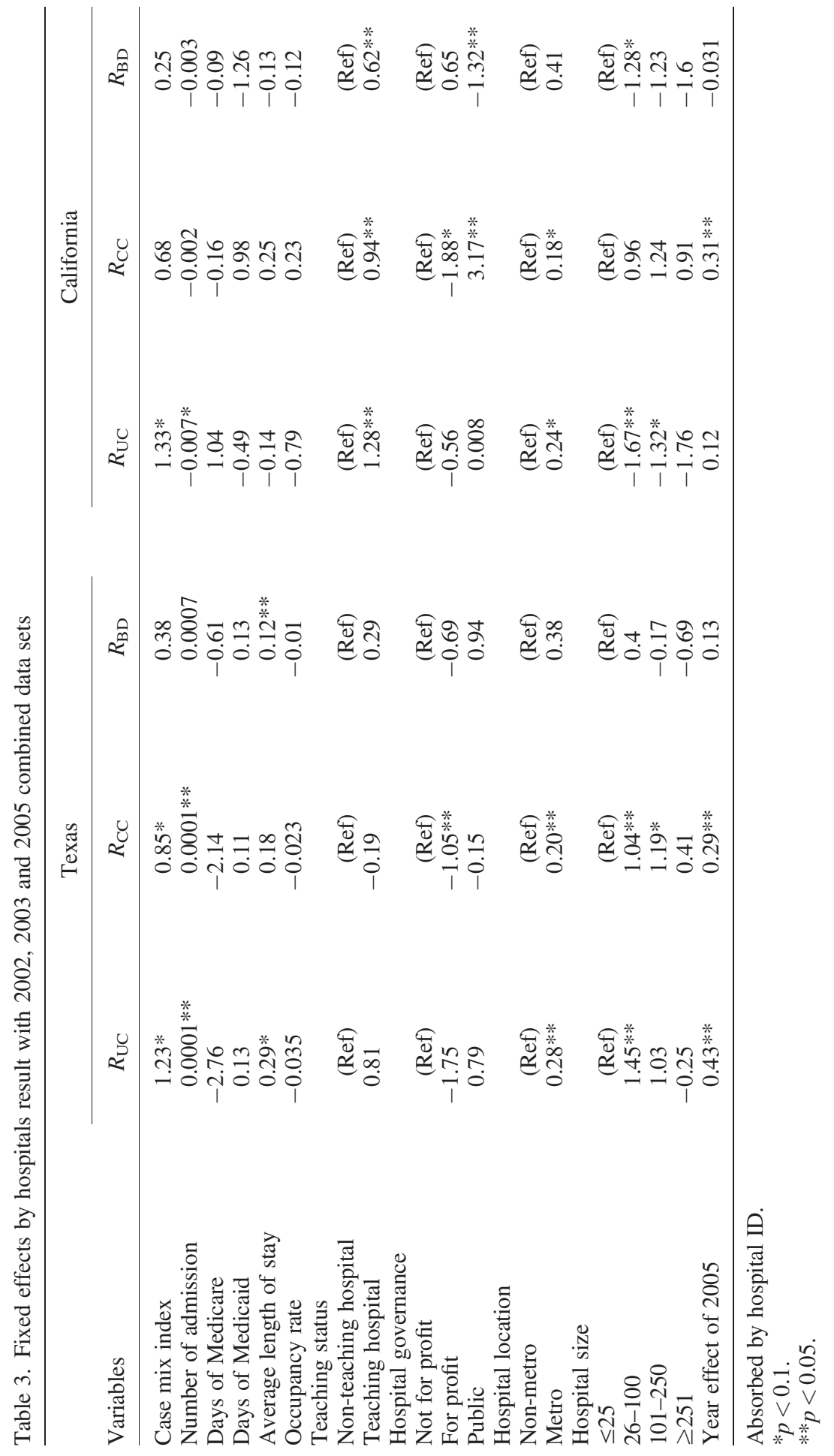


Safety Code, 2008). Texas non-profit hospitals, on the other hand, have the following community benefit laws that abide the hospitals to provide pre-established amount of charity care and government-sponsored unreimbursed care: (i) in accordance to the need of the community, tax exempt benefits and the hospital's financial reserves, (ii) in an amount equal to or more than the advantages derived by the hospitals due to their tax exempt status or (iii) in an amount equivalent to at least $4 \%$ of the net patient revenue. Some non-profit hospitals in Texas also provide charity care and community benefits in an amount equivalent to about $5 \%$ of the net patient revenue (Texas Health and Safety Code, 2007; OSHPD, 1998; Sutton and Stensland, 2004). Many studies have shown that NFP hospitals provide more charity care compared with FP hospitals Herzlinger and Krasker (1987); Lewin et al., 1988; Thorpe and Phelps, 1991; Norton and Staiger, 1994; Weissman, 1996). There are some possible reasons contributing to the charitable nature of the NFP hospitals. NFP hospitals share disproportionate burden of charity care compared with FP hospitals, which in turn further discourages FP hospitals from providing charity care. This might be the case in Texas as previous studies have shown that NFP hospitals in Texas sometimes generously provide community benefits more than they are required to, even in the absence of community benefit and charity care laws in order to promote their self interests such as conducting research and training of graduate medical students (Clement et al., 1994; Buchmueller and Feldstein, 1996; Sanders, 1993; Herzlinger and Krasker, 1987; Spencer, 1998). The unreimbursed care of NFP hospitals might be the result of unreimbursed care of Medicaid and Medicare patients. Many times, there is "crowding out" by NFP hospitals leading to delivery of extra charity care by NFP hospitals. This extra charity care delivered by NFP hospitals leads to a reduction in the amount of charity care to be delivered by FP hospitals. Compared with Texas, our study shows more "crowding out" by NFP hospitals in California where NFP hospitals $(n=191)$ are almost double in number compared with FP hospitals $(n=86$; Table 1$)$. This might be one of the reasons that charity care is significant in California. Even though FP hospitals deliver a small amount of charity care, it might help them build goodwill that might further attract business from different buyers of healthcare services. Patients cannot easily differentiate between the quality of care obtained in NFP and FP hospitals. Hospitals with strong goodwill are presumed to deliver quality care to their patients. Thus, FP hospitals can attract business and use the profits generated due to the same for expansions and mergers (Seay et al., 1986; Hirth, 1997; Marsteller et al., 1998).

For-profit hospitals, even though providing community service to the communities, choose to serve and select markets where there is less likelihood of providing a sizeable proportion of charity care (Seay et al., 1986). A study conducted by the University of California at Los Angeles located 12 metropolitan statistical areas (MSAs) with higherthan-average uninsured rates in Texas and California, which have large concentrations of immigrants (Commonwealth Fund, 2000). The study noted that in these MSAs, the Hispanic population accounts for a large percentage of the moderate-income and lowincome residents who are less likely to be insured (Texas Department of Insurance, 2004). According to our study, Texas has doubled the number of hospitals in the metropolitan areas $(n=298)$ compared with the non-metropolitan areas $(n=119)$, compared with California, which has almost equal number of hospitals in the metropolitan $(n=192)$ and non-metropolitan areas $(n=160$; Table 1$)$. Most of the NFP hospitals are 
located in the metropolitan areas compared with the non-metropolitan areas in Texas (Texas Fact Sheet, 2006). The higher number of NFP hospitals located in the metropolitan areas of Texas might be contributing to significant uncompensated care in Texas. The metropolitan/non-metropolitan differences found in this study substantiate claims that metropolitan hospitals, which are non-profit, act as major drivers in increasing hospital bad debt and fulfilling the need for charity care. Hence, policy makers need to divert their attention to hospitals located in the metropolitan areas.

From 2002 to 2007, the cumulative rise in the healthcare premiums was as high as $78 \%$ compared with $17 \%$ of cumulative inflation and $19 \%$ of cumulative wage growth, respectively. Increase in the healthcare premiums leads to people paying more for their insurance plan compared with the previous years. The type of insurance plan determines the coverage of services and the out-of-pocket expenditure borne by people. In 2004, the average out-of-pocket expenditure amounted to about 34\% (Kaiser Family Foundation, 2007). Increase in the healthcare premiums can be attributed to factors such as (i) increases in prescription drug prices, (ii) increases in prescription drug usage, (iii) increases in physician fees, (iv) increases in specialist physician visits, (v) increases in home health, outpatient surgery, physical therapy and other ancillary services and (vi) administrative costs for health insurance related to case management, disease management, fraud and abuse prevention. The increase in health insurance premiums is causing more employees not to have any insurance coverage, and being uninsured causes more patients to visit the Emergency Room (ER) and have bad debts. The increased number of patients visiting the ER and the budget cut pressure further increase the burden of uncompensated care shouldered by the non-profit hospitals, which is in turn being cost shifted to patients with insurance. Thus, the numbers of uninsured people increase further, increasing the burden of uncompensated care faced by hospitals (Strayhorn, 2005). However, hospital bad debts account for a small portion of increase in annual hospital expenditures as well as the medical expenditures borne by the insurers. Combined efforts by the state government as well as the hospitals could assist the hospitals in alleviating their financial losses. The policy implications for the state government include initiating changes in several insurancerelated factors such as reduction of cuts to the Medicaid program, expansion of the SCHIP program, increase in the federal funding for Medicaid program, encouragement to purchase insurance by providing federal tax credits and provision of Medicaid waiver to ensure affordable insurance for indigent population (Texas Comptroller of Public Accounts, 2001a, 2001b; Walker et al., 2005). The hospitals can divert the ER patients to community health centers $(\mathrm{CHCs})$ operated by primary care providers (PCPs), which will ensure provision of cost-effective healthcare services to indigent populations. This not only reduces uncompensated healthcare costs but also leads to proper dissemination of information by the PCPs to patients, thereby taking care of the non-emergent healthcare needs of some of the ER patients in the long run. However, it is essential that sustainable partnerships be built between the hospitals and the CHCs (Bennett et al., 2007; Nykamp and Ruggles, 2000; Davidson et al., 2003, McCarthy et al., 2002; Steiner et al., 2002).

A review of the literature provides evidence of changes in the hospitals' spending behavior impacted by cost containment (Hadley et al., 1996). Data also illustrate differences in the uncompensated care and charity care after 2004 compared with 
data from 2002 to 2003. Healthcare policy makers can evaluate hospital's spending and measure the consistency of provision of uncompensated care. This study provides an important policy directive in terms of assessing unintended consequences, if any, to implement an uncompensated care policy.

\section{LIMITATIONS}

There are several limitations to this analysis. Primarily, there is a possibility of selection history threat that occurs when the outcomes of an event are measured between the preobservation and post-observation periods. In this case, there is a potential for such a threat given the possibility of the uncompensated care legislature actions suspending the future funding for Medicaid beneficiaries occurring during the same time frame as the Texas budget cut in 2004. Although this may only affect the Medicaid population, it can still result in skewed results. As a potential solution, Medicaid patients may be analyzed separately to account for such a threat. Secondly, because of data unavailability, this study excluded some of the market factors such as HMO penetration and self-insured paying patients that could impact uncompensated care. There was a lack of consistency in capturing these variables in the annual surveys. The survey did not differentiate patients who possess insurance but still contribute to bad debt expenses. These variables, if could be captured, would potentially provide a more accurate assessment about which of the dependent variables (charity care or bad debt expenses) would significantly affect uncompensated care burden borne by hospitals.

\section{CONCLUSIONS}

In spite of the limitations, this study provides an important step for filling a gap towards understanding spending behaviors associated with uncompensated care. The study provides an estimate of the uncompensated care charge with respect to net patient revenue and its association with resource allocation among hospitals based on the type of hospital governance. Not only does it highlight the need to look at trends in uncompensated care spending by hospitals, but it also shows the need to identify and study trends across the different types of hospitals.

\section{ACKNOWLEDGEMENT}

This work was supported by Gachon University (2012-R049). The authors have no competing interests.

\section{REFERENCES}

American Hospital Association (AHA). 2004. Fast facts on U.S. hospitals from AHA Hospital Statistics. Data

Copyright @ 2012 John Wiley \& Sons, Ltd. from 2004 survey. http://www.aha.org/aha/resource center/fastfacts/fast_facts_US_hospitals.html.

Int J Health Plann Mgmt 2012; 27: 88-103.

DOI: $10.1002 / \mathrm{hpm}$ 
American Hospital Association (AHA). 2009. AHA Annual Survey Database ${ }^{\mathrm{TM}}$ fiscal year 2009. Data from 2009 survey. http://www.ahadata.com/ahadata/html/ AHASurvey.html

American Hospital Directory (AHD). 2009. Inpatient utilization based on Medicare IPPS claims data. From http://www.ahd.com/inpatient.php?hcfa_id=b41bbb2c2abaf10553d702a9e9672a1d\&ek140d2c466f6723aa b6cfe7a2df981c75

Bennett KJ, Moore CG, Probst JC. 2007. Estimating uncompensated care charges at rural hospital emergency departments. J Rural Health 23(3): 258-263.

Bryce H. 2001. Capacity considerations and community benefit expenditures of nonprofit hospitals. Health Care Manage Rev 26(3): 24-39.

Buchmueller T, Feldstein P. 1996. Hospital community benefits other than charity care: implications for tax exemption and policy. Hosp Health Serv Adm 41(4): 461-471.

California Health and Safety Code - Section 127340127360. 2008. From http://www.leginfo.ca.gov/cgibin/displaycode?section=hsc \&group=127001-128000 $\&$ file $=127340-127360$

California Office of Statewide Health Planning and Development. 1998. Not-for-profit hospital community benefit legislation: report to the legislature. Sacramento: California Office of Statewide Health Planning and Development From http://www. oshpd.ca.gov/HID/SubmitData/CommunityBenefit/ notforprofitlegislation.pdf

Centers for Medicare and Medicaid Services. 2009. Payment system fact sheet series-acute inpatient prospective payment system. From http://www.ahd.com/ AcutePaymtSysfctsht_JAN09.pdf

Centers for Medicare and Medicaid Services. 2010. Office of the Actuary, National Health Statistics Group, National Health Care Expenditures Data.

Clement J, Smith H, Wheeler J. 1994. What do we want and what do we get from not-for-profit hospitals? Hosp Health Serv Adm 39(2): 159-178.

Coughlin T, Liska D. 1997. The Medicaid disproportionate share hospital payment program: background and issues. From http://www.urban.org/UploadedPDF/ anf_14.pdf

Dalpatadu KC, Eliya RR, Sikhrajapathy L. 2007. Performance reviews of provincial and line ministry healthcare services for the Annual Health Forum Sri Lanka Health System Development Project. From http://203.94.76.60/AHF/pdf/CD03/Table_of_ Content_0-5.pdf

Davidson R, Giancola A, Gast A, Ho J, Waddell R. 2003. Evaluation of access, a primary care program for indigent patients: inpatient and emergency room utilization. J Community Health 28(1): 59-64.
Davis K. 1991. Inequality and access to health care. Milbank $Q$ 69(2): 253-273.

Desai KR, Van Deusen Lukas C, Young GJ. 2000. Public hospitals: privatization and uncompensated care. Health Aff 19(2): 167-172.

Dor A, Farley D. 1996. Payment source and the cost of hospital care: evidence from a multiproduct cost function with multiple payers. $J$ Health Econ 15(1): $1-21$.

DSHS/AHA/THA Annual Survey of Hospitals. 2006. Hospital Survey Unit, Center for Health Statistics, Texas Department of State Health Services.

Fishman L, Bentley J. 1997. The evolution of support for safety-net hospitals. Health Aff 16(4): 30-48.

Gaynor M, Anderson G. 1995. Uncertain demand, the structure of hospital costs, and the cost of empty hospital beds. J Health Econ 14(3): 291-317.

Government Accountability Office. 2005. Nonprofit, forprofit, and government hospitals: uncompensated care and other community benefits. GAO-05-743T, retrieved on 21 Oct 2005 from http://www.gao.gov/ cgi-bin/getrpt?GAO-05-743T

Grannemann T, Brown R, Pauly M. 1986. Estimating hospital costs: a multiple-output analysis. J Health Econ 5(2): 107-128.

Hadley J, Holahan J. 2004. The cost of care for the uninsured: what do we spend, who pays, and what would full coverage add to medical spending? The Kaiser Commission on Medicaid and Uninsured, retrieved on 20 Oct 2007 from http://www.kff.org/uninsured/ 7084.cfm

Hadley J, Zuckerman S, Iezzoni LI. 1996. Financial pressure and competition. Changes in hospital efficiency and cost-shifting behavior. Med Care $\mathbf{3 4}$ (3): 205-219.

Harris BL, Stergachis A. 1990. The effect of drug copayments on utilization and cost of pharmaceuticals in a health maintenance organization. Med Care $\mathbf{2 8}$ (10): 907-917.

HCIA Inc. 1997. The Comparative Performance of U.S. Hospitals: the Sourcebook. Deloitte \& Touche LLP: Chicago, IL.

Herzlinger R, Krasker W. 1987. Who profits from nonprofits? Harv Bus Rev 87: 93-106.

Hirth R. 1997. Competition between for-profit and nonprofit health care providers: can it help achieve social goals? Med Care Res Rev 54: 414-438.

Hoadley JF, Cunningham P, McHugh M. 2004. Popular Medicaid programs do battle with state budget pressures: perspectives from twelve states. Health Aff 23(2): 143-154.

Hsieh H, Clement DG. 2010. Impacts of market and organizational characteristics on hospital efficiency and uncompensated care. Health Care Manage Rev 35(1): 77-87.

Int J Health Plann Mgmt 2012; 27: 88-103. 
Kaiser Commission on Medicaid and the Uninsured. 2004. Kaiser Family Foundation of children's Medicaid and SCHIP in Texas: tracking the impact of budget cuts.

Kaiser Commission on Medicaid and the Uninsured. 2005. Kaiser Family Foundation of SCHIP enrollment in 50 states.

Kaiser Family Foundation. 2007. Kaiser Family Foundation of your resource for health policy information, research, and analysis: trends in health care costs and spending.

Lewin L, Eckels T, Miller L. 1988. Setting the record straight: the provision of uncompensated care by not-for-profit hospitals. $N$ Engl $\mathrm{J}$ Med 318: 1212-1215

Mann J, Melnick G, Bamezai A, Zwanziger J. 1995. Uncompensated care: hospitals' responses to fiscal pressures. Health Aff 14(1): 263-270.

Marsteller J, Bovbjerg R, Nichols L. 1998. Nonprofit conversion: theory, evidence, and state policy options. Health Serv Res 33: 1495-1535.

Martin S, Frick AP, Shwartz M. 1984. An analysis of hospital case mix, cost, and payment differences for Medicare, Medicaid, and blue cross plan patients using DRGs. Inquiry 21(4): 369-379.

McCarthy ML, Hirshon JM, Ruggles RL, Docimo AB, Welinsky M, Bessman ES. 2002. Referral of medically uninsured emergency department patients to primary care. Acad Emerg Med 9(6): 639-642.

Melnick GA, Zwanziger J. 1995. State Health care expenditures under competition and regulation, 1980 through 1991. Am J Public Health 85(10): 1391-1396.

Norton E, Staiger D. 1994. How Hospital Ownership Affects Access to Care for The Uninsured. Rand $J$ Econ 25: 171-185.

Nykamp D, Ruggles D. 2000. Impact of an indigent care program on use of resources: experiences at one hospital. Pharmacotherapy 20(2): 217-220.

Phelps C. 1986. Cross-subsidies and charge-shifting in American hospitals. In Uncompensated Hospital Care: Rights and Responsibilities, Sloan F, Blumstein J, Perrin J (eds.). Johns Hopkins University Press: Baltimore, MD

Robinson J, Luft H. 1985. The impact of hospital market structure on patient volume, average length of stay, and the cost of care. J Health Econ 4(4): 333-356.

Rosko M. 2004a. Performance of U.S. teaching hospitals: a panel analysis of cost inefficiency. Health Care Manage Sci 7(1): 7-16.

Rosko M. 2004b. The supply of uncompensated care in Pennsylvania hospitals: motives and financial consequences. Health Care Manage Rev 29(3): 229-239.

Sanders S. 1993. Measuring charitable contributions: implications for the nonprofit hospital's tax-exempt status. Hosp Health Serv Adm 38(3): 401-418.
Seay J, Vladek B, Kramer P, Gould D, McCormack J. 1986. Holding fast to the good: the future of the voluntary hospital. Inquiry 23: 253-260.

Simpson J, Shin R. 1998. Do nonprofit hospitals exercise market power? Int J Econ Bus 5(2): 141-157.

Spencer C. 1998. Do uncompensated care pools change the distribution of hospital care to the uninsured? $J$ Health Politics Pol Law 23(1): 53-73.

Steiner J, Price D, Chandramouli V, Goodspeed J. 2002. Managed care for uninsured adults: the rise and fall of a university-base program. Am J Manag Care $\mathbf{8}$ (7): 653-661.

Strayhorn CK. 2005. The uninsured: a hidden burden on Texas employers and communities. Office of the Comptroller in Texas, retrieved on 25 Oct 2010 from http://www.window.state.tx.us/specialrpt/uninsured05/ 96-1128.pdf

Sutton J, Stensland J. 2004. Promoting accountability: hospital charity care in California, Washington State, and Texas. J Health Care Poor Underserved 15(2): 237-250.

Texas Comptroller of Public Accounts. 2001a. Encourage federal tax credits for individuals buying private health insurance. From http://www.window.state.tx. us/etexas2001/recommend/ch08/hhs02.htm.

Texas Comptroller of Public Accounts. 2001b. Encourage the federal government to expand "safety-net" programs in Texas. From http://www.window.state.tx.us/ etexas2001/recommend/ch08/hhs04.html.

Texas Department of Insurance. 2004. Working Together for a Healthy Texas: Texas State Planning Grant (Austin, Texas), p. 15

Texas Health and Safety Code - Section 311.042. 2007. Definitions, from http://law.onecle.com/texas/health/ 311.042.00.html

Texas Health and Safety Code - Section 311.045. 2007. Community benefits and charity care requirements, from http://law.onecle.com/texas/health/311.045.00.html

The Commonwealth Fund Quarterly: A Digest of Current Work in Health Policy and Practice 2000. 6(3).

Thorpe K, Phelps C. 1991. The social role of not-for-profit organizations: hospital provision of charity care. Econ Inq 29: 472-484.

Thorpe KE, Seiber E, Florence C. 2000. Hospital conversions, margins, and the provision of uncompensated care. Health Aff 19(6): 187-195.

U.S. Census Bureau. 2004. Historical health insurance. Retrieved on 24 Sep 2007 from http://www.census. gov/hhes/www/hlthins/historic/index.html

Vladeck B. 2006. Paying for hospitals' community services. Health Aff 25(1): 34-43.

Walker J, Pan E, Johnston D, Adler-Milstein J, Bates DW, Middleton B. 2005. The value of health care information exchange and interoperability. Health Aff (Millwood) Suppl Web Exclusives: W5-10-W5-18.

Int J Health Plann Mgmt 2012; 27: 88-103. 
Wedig G, Sloan F, Hassa M, Morrisey M. 1988. Capital structure, ownership, and capital payment policy: the case of hospitals. $J$ Financ $\mathbf{4 3}(1)$ : 21-40.

Weissman J. 1996. Uncompensated hospital care: will it be there if we need it? JAMA 276: 823-828.

Weissman JS. 2005. The trouble with uncompensated hospital care. $N$ Engl J Med 352(12): 1171-1173.
Wright EL. 1998 Are you getting your money's worth from nonprofit hospitals? Washington DC. Through the looking glass. Citizens Against Government Waste. March 9, 2007. From http://www.cagw.org/ upload/CommnityBenefit.pdf.

Young GJ, Desai K. 1999. Non-profit hospital conversions and community benefits: new evidence from three states. Health Aff 18(5): 146-155. 